\title{
A Study on the Cultural Influence on Business Negotiations: Evidence from Bangladesh
}

\author{
Peng Zhangwen ${ }^{1}$, Md. Rakibul Hoque ${ }^{2}$ \\ ${ }^{1}$ Shanghai Electric Power Construction Co. Ltd., Shanghai, China \\ ${ }^{2}$ Department of Management Information Systems, University of Dhaka, Dhaka, Bangladesh \\ Correspondence: Md. Rakibul Hoque, Department of Management Information Systems, University of Dhaka, \\ Dhaka, Bangladesh.
}

Received: November 1, 2017

Accepted: December 11, 2017 Online Published: December 19, 2017

doi:10.5539/ibr.v11n1p157

URL: https://doi.org/10.5539/ibr.v11n1p157

\begin{abstract}
Although many indi viduals speak of Bangladesh as a booming trading partner, in reality, negotiating for business in Bangladesh is systematic work. In the age of globalization and an increasingly globally integrated economy, businesspeople across the world negotiate with counterparts of different cultural backgrounds more often than ever before. However, little research has been conducted to identify the influence of culture on business negotiation in Bangladesh. This study examines the relationship between culture and negotiation style in Bangladesh. The data were collected from Bangladeshi business executives who have enormous experience in business dealings. The results suggest that it is important to consider the culture within a country when examining positive business outcomes.
\end{abstract}

Keywords: business negotiation style, culture, Bangladesh

\section{Introduction}

Negotiation styles and practices differ from culture to culture (Salacuse, 1998). From a behavioral perspective, as individuals in different cultures resolve their social interaction issues differently, their negotiation practices vary (Brett, 2017). In the age of globalization, businesspeople across the world negotiate with counterparts of different cultural backgrounds more often than ever before. Due to this change in today's global economic environment, both top executives and researchers need to understand how culture influences negotiations (Gelfand et al., 2013). Today, many organizations see negotiation practice as a competitive necessity when negotiating with partners from other regions (Sobral et al., 2008). For this reason, cross-cultural negotiators generally leave more value on the table when trying to capture their counterparts' interests and trade them off against their own interests (Brett, 2017).

Successful negotiation in business is one of the greatest challenges that the top executives in an international environment face when doing business with their foreign counterparts (Deresky, 2017). The negotiating process with members of a foreign culture is both complex and dynamic, requiring significant time and effort for top executives. A lack of knowledge of the concurrent influence of culture and context can be problematic from a practical perspective, as it may render top executives ill prepared for business negotiations (Gelfand et al., 2013).

Currently, conducting successful business negotiations with Bangladeshis is a significant challenge faced by foreign businessmen, and vice versa. Bangladesh is a target market for foreign investors who are keen to invest in various types of businesses. Many large and small, and new and old Asian companies have sought to take advantages of Bangladesh's cheap labor while positioning themselves to market their goods to the fast-growing Bangladeshi middle class (Saha, 2016). The industries of Bangladesh have witnessed rapid growth over the years and still receive high investments from overseas entrepreneurs through foreign direct investment.

Many countries have moved their business operations and manufacturing bases to Bangladesh, as it is strategically important as an economic hub for Northeast India, Nepal, and Bhutan. The country is also considered as a potential gateway for China (Rahmatullah, 2009). Nowadays a strategic highway is proposed from the southwest of China to south of Bangladesh via Myanmar.

Therefore, it would be very meaningful to identify and understand the cultural dimensions that influence business negotiation style in a Bangladeshi context. Moreover, considering the recent surge in the privatization 
of many public companies and the opening up of their markets in foreign regions, this study is even timelier. Thus, this study seeks to understand the cultural influence on the negotiation style of Bangladeshi business executives. In this process, the following sections will begin with a contextual and cultural outline of Bangladesh to learn about the country's existing cultural practices.

\section{Literature Review}

The term "culture" is extremely broad. It includes history, what has been learned, habits, morals, values, customs, and art. It is defined as "the socially spread behavior patterns, norms, beliefs, and values that exist in a specific community" (Salacuse, 1998). There are broad differences between the cultures of different societies, and, similarly, there are differences within the same culture. A country's approach to negotiation is embedded in the culture (shared beliefs) of its people, and their culture is influenced by the historical development of their country (David et al., 1994). In this regard, many books are found in the literature with country-specific titles, such as "Negotiating with the Chinese," "Negotiating with the Arabs," "Negotiating with the North Americans," "Negotiating with the Europeans," and so on.

Negotiations take place among people all the time for two main reasons: (i) to develop something new that neither of the two parties could create on their own and/or (ii) to resolve an issue or dispute (Abbasi et al., 2017). There exist different types of negotiating styles for different business purposes, such as collaboration, compromise, accommodation, competition, and e ven ending negotiations and dissolving business (Chang, 2012), in which the negotiators have to deal with different perceptions, contradictory business goals and priorities, dichotomous reasoning and thoughts, and different languages and cultures (Kramer \& Herbig, 1997). According to Chang (2012), conflicts may arise even when both negotiators share the same culture and language, due to the fact that the negotiators may have different values and follow different styles of action. The negotiation process is considerably more complex in the context of cross-cultural negotiations (Sebenius, 2002).

It is argued that the practice of cross-cultural negotiation is much different from that of intra-cultural negotiations (Elahee et al., 2002). It is more important to sufficiently understand precisely how cultural dimensions affect the practice of cross-cultural negotiation (Elahee et al., 2002). The culture can govern the ethical codes of the negotiators, and it also has effects on the negotiators' ways of thinking and behaviors (Jiang, 2013). According to Ahammad et al. (2016), there are three stages in international business negotiation, namely, pre-negotiation, negotiation, and post-negotiation, and all of these stages are influenced by culture. On the other hand, Salacuse (1991) identified ten negotiating factors that can be influenced by culture. These factors are negotiating goals, attitudes to the negotiating process, personal styles, styles of communication, time sensitivity, emotionalism, agreement form, agreement building process, team organization, and risk-taking.

A literature review by Peleckis (2013) shows 47 cultural dimensions that might influence the negotiation process. However, not all those dimensions are empirically examined with sufficient detail. According to a previous study (Sobral et al., 2008), Hofstede's cultural dimensions are also useful to consider in order to obtain a solid contextual overview of the influence of deeply enrooted cultural dimensions on negotiation.

\section{Setting the Context: Bangladesh}

Bangladesh is, by nature, historically a business hub and has been treated as such since ancient times, even before becoming independent. In ancient times, Bangladesh was called the heaven of wealth and attracted Western and Middle Eastern business people (Van, 2009). Businessmen from various parts of the world came to Banga (now Bangladesh) for commerce and the trade of various goods and products in this region before returning to their home countries. Among them, Portuguese, English, French, Dutch, and Arab traders were prominent and well known. Business relationships were developed between Bangas' Banik (local businessmen) and foreign businessmen of different origins with their own styles. Local businesses had to mix and make business deals with foreign buyers and traders. Accordingly, cultural issues naturally came to be and were transmitted in both directions, so human behavior, values, and thoughts played a vital role in negotiation and bargaining (Hashim, 2010).

Over the past several decades, there has been a tremendous increase in international business and trade as countries have privatized their publicly owned business and have opened their markets to foreign products and investment (Adhikary, 2010). Bangladesh is now considered to be one of the important economic cases and interesting places to do business in the world. Despite suffering from political instability, intense conflicts, domestic strife, a financial crisis, and inadequate infrastructure, Bangladesh continues to grow its economy by an average of 6.3 percent over the past seven years (FY2009-10 to FY2015-16). According to the final estimates of the Bangladesh Bureau of Statistics, GDP growth in the fiscal year 2015-16 stood at 7.11 percent (BBS, 2016), significantly up from 6.55 percent in FY2014-15. The economic capacity of Bangladesh has seen rapid positive 
changes in recent years. Its per-capita income has reached $\$ 1,416$, and it has been committed to continuing the development efforts along with Commonwealth of Nations, the D-8 Organization for Economic Cooperation, the EU, the South Asia Association for Regional Cooperation, the International Monetary Fund, the World Bank, the World Trade Organization, the Asia Infrastructure Investment Bank, and the Asian Development Bank. The economic sector of the country has been able to utilize internal resources and cheap labor opportunities to attract economic entrepreneurs, national investors, policymakers, foreign investors, and economic development partners.

In the early 1980s, there were about 12 RMGs in the country, but at present, more than 4,000 RMGs prevail and produce to meet the internal and foreign demand. Industries such as plastics, textiles, garments, garment accessories, leather, agriculture, frozen food, food processing, medicine, real estate, shipping, ceramics, cement, information technology, and small and medium enterprises have been established to attract foreign investment and create employment opportunities for the unemployed members of the population (Yunus, \& Yamagata, 2012).

\section{The Cultural Spectrum in Bangladesh}

As Bangladesh was ruled by sultanate emperors and was then a colony of the British Empire around 200 years, the culture is very diverse (Reaiche et al., 2016). This cultural spectrum is widely covered by every sphere of people's lives. As a result, it is very difficult to explain in a single dimension. There exist multiple subcultures stemming from multiple nationalities. In order to understand the impact of culture on Bangladeshi business negotiators, it is important to consider certain cultural contexts. Like many other colonized countries, Bangladesh went through centuries of struggle before finally attaining independence. Tribal and religious subcultures are very well practiced in many ancient towns, and the number of archeological sites and attractions can be overwhelming (World Archaeology, 2002).

Bangladesh has a rich, diverse culture. Its deeply rooted heritage is thoroughly reflected in its architecture, literature, dance, music, painting, and clothing. The three main religions of Bangladesh (Islam, Hinduism, and Buddhism) have had a significant influence on its history and culture. Therefore, cultural diversity is present in Bangladesh. This cultural diversity can also be seen in folklore, tribal dances, festivities, and even in contemporary pop songs. Understanding the cultural values and diversity in Bangladesh is important for negotiators because these may influence the negotiation process involving Bangladeshi people and businessmen (Abdullah et al., 2011).

The primary language is Bangla, which is called Bengali by most nonnatives. Bangla varies by region, and a person from one district may not understand the language of a person from another district. However, differences in dialect consist primarily of slight differences in accents or pronunciations and minor grammatical usages. Among the Muslim Bangladeshis, personal interactions are initiated with the greeting "As-Salaam-Alaikum" ("Peace be upon you"), to which the required response is "Wa-Alaikum-Salaam" ("And upon you, peace"). Among Hindus, the correct greeting is "Nomoshkar," as the hands are brought together under the chin. Differences in age and status are marked through language conventions. Individuals with higher status are not addressed by personal names; instead, a title or kinship term is used.

As is mentioned above, as a result of around 200 years of British imperialism in this region, a mixture of Western and Eastern cultural and behavioral approaches still exist here and influence business practices and negotiations. For this reason, negotiators who are able to identify the specific cultural influences in the negotiation styles of their counterparts have a clear advantage in the negotiation process (Abbasi et al., 2017).

\section{Methodology}

This study is concerned with cultural influence on business negotiations in Bangladesh and measuring and examining the relationship between culture and business negotiation style. This section gives details about questionnaires, the data collection process, and data analysis. The data for this study were collected through a semi-structured questionnaire that contains forty questions within three parts. Every part contains different types of questions. Part A contains closed- and open-ended questions, comprising nine questions total. Part B contains scale questions for measuring the behavioral dimensions of business negotiators' styles that might be culturally specified. The scale was developed on the basis of theoretical suggestions from Salacuse (1999), Weiss and Stripp (1995), and Hofstede (2017) and consists of sixteen questions. These scaling questions consist of two opposite questions with mutually exclusive sentences explaining negotiation dimensions and behaviors. The participants had to choose one sentence from the set of two sentences. Another short section includes a Likert scale around the necessity of negotiation skills comprising seven questions. Finally, part $\mathrm{C}$ includes respondent information and comprises eight questions. 
A cross-sectional face-to-face questionnaire survey method was used for this study. The survey was conducted during the two-month period from August 2017 to September 2017. The data were collected from more than 50 Bangladeshi business executives. These participants were chosen based on convenience sampling method. These respondents were mostly business executives who had long-term previous experience with foreign business. The participants were asked to respond to the selected statements to gauge cultural dimensions based on some behavioral variables describing them. The study participants were $86 \%$ male and $14 \%$ females. The average age of the respondents was 41 years. The collected data were analyzed using Microsoft Excel and SPSS.

\section{Results and Discussion}

Negotiation style varies from business to business, environment to environment, and based on experience, personality, bureaucracy, and other cultural dimensions. This section will focus on how culture influences Bangladeshi negotiators and how they act in a negotiation?

This study finds that, on average, respondents have dealt with five foreign organizations, and $45 \%$ of them have completed more than seven deals with foreign organizations (Figure 1). On the other hand 38 percent of respondents have experienced more than five successful dealings (Figure 2). It can be inferred that the respondents are experienced and successful in their business negotiations.

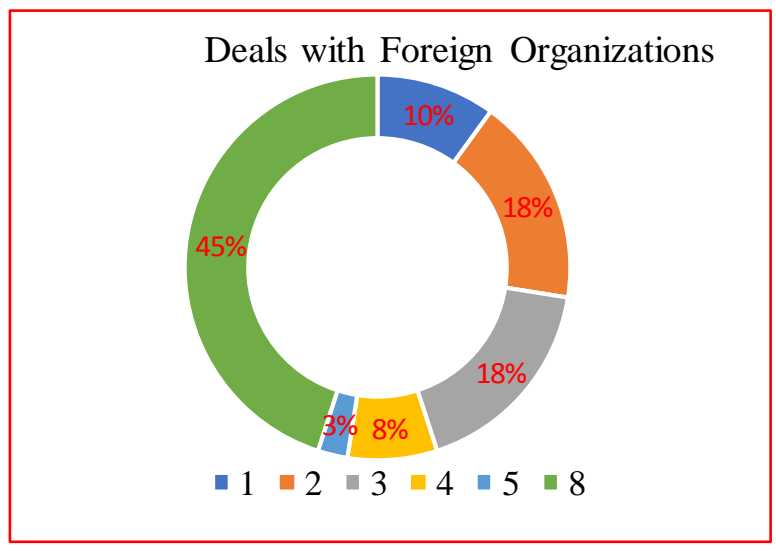

Figure 1. Deals with Foreign Organizations

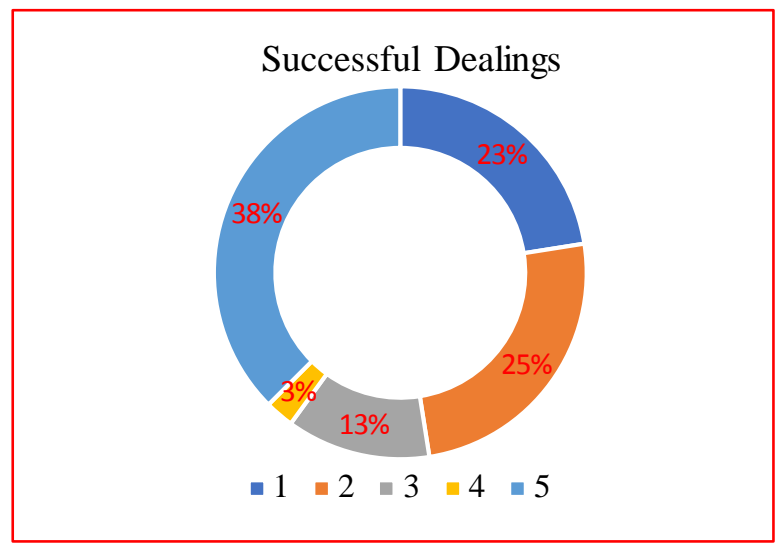

Figure 2. Successful Dealings

\subsection{Attitudes and Preferences for Business Meeting Times and Places}

Data collected from survey show that $77 \%$ of business negotiators in Bangladesh prefer to participate in or arrange a meeting in their own country and that only $23 \%$ of them want to arrange a meeting in the host country (Figure 3). It is very surprising that no one prefers to arrange a meeting in a third country. This data implies that Bangladeshi negotiators are not willing to take risks. About $35 \%$ of respondents prefer to start meetings in the afternoon, whereas $30 \%$ of respondents prefer mornings (Figure 4). This finding is consistent with the culture of Bangladesh, as Bangladeshi people usually like to do important work in the morning and afternoon.

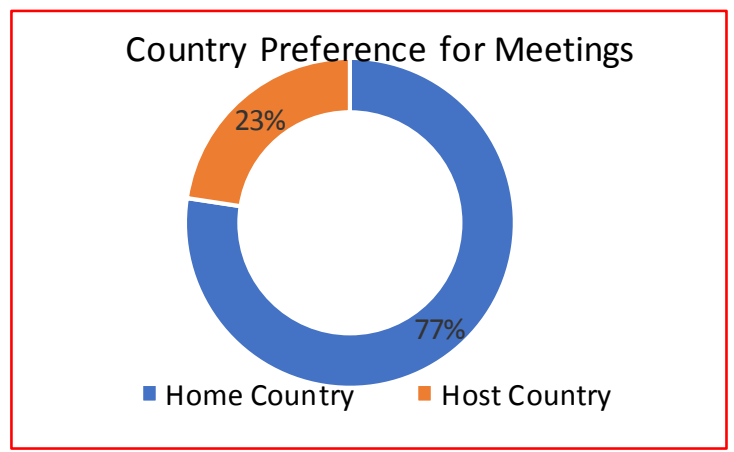

Figure 3. Country Preference for Meetings

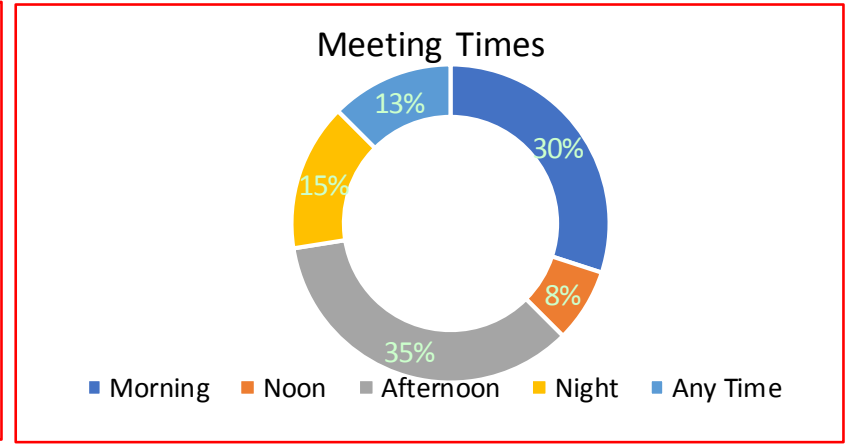

Figure 4. Meeting Times

The business deal success rate of Bangladeshi business negotiators is highest with Chinese counterparts (Figure 5). This result is based on the number of transactions and the amount of dealings with Chinese companies. From Geert Hofstede's (2017) cultural dimension study, China is a highly powerful nation, and Chinese negotiators 
prefer to work collectively and are success oriented. Furthermore, they want to build long-term relationships with their counterparts. The other three countries, Germany, India, and the United Kingdom (UK), follow China in terms of Bangladeshi business negotiations.

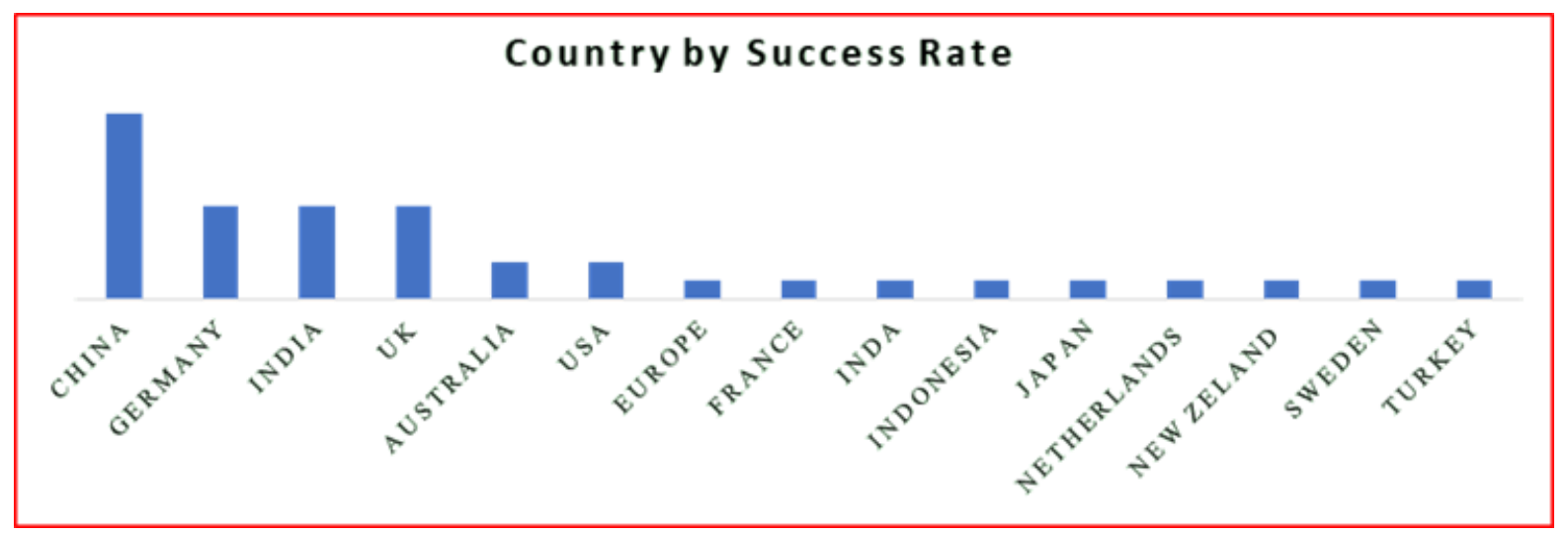

Figure 5. Country by Success Rate

\subsection{Comfortability by Country}

Participants were asked about which country they feel most easy and comfortable to work with. They state that they are very comfortable with the UK, followed by the USA, Australia, China, and Germany (Figure 6). As per the lens of the 6-D model in Hofstede Insights, these five nation's masculine scores range from 55 to 66, so this dimension indicates that all of these countries belong to a masculine society that is success-oriented and driven. Bangladeshi negotiators share the same characteristics with those countries.

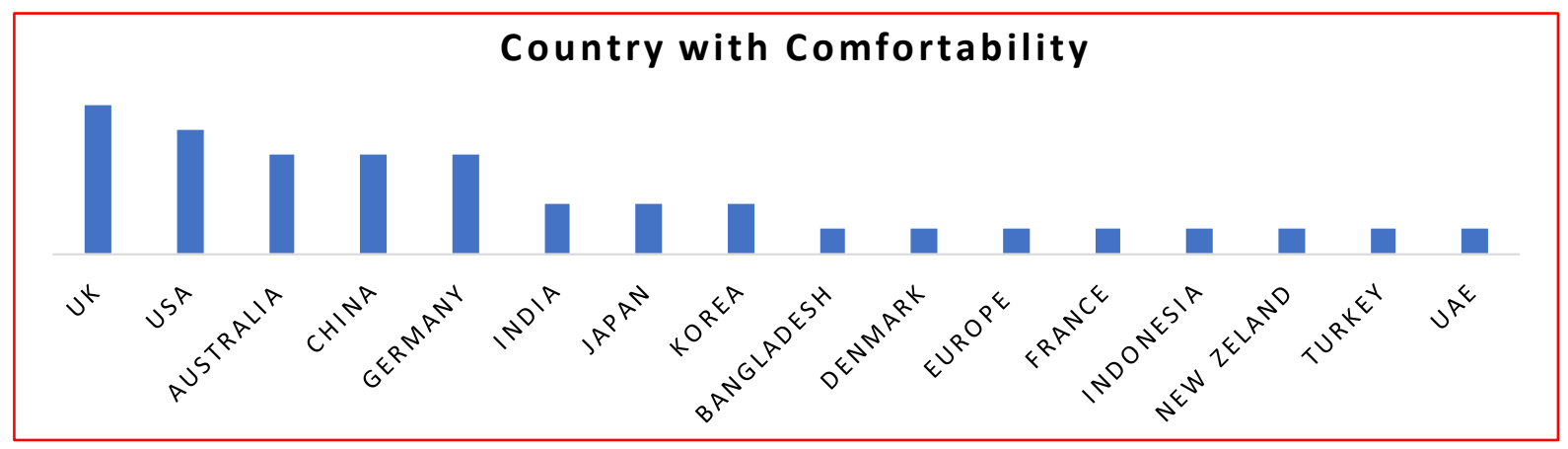

Figure 6. Country with Comfortability

\subsection{Nature of Negotiation Style}

Individual perceptions about the negotiation process are widely dependent on the nature of the negotiation, which refers to how a negotiator thinks about the negotiating process. Negotiation activity includes basic concepts of negotiation, such as collaboration or competition, whether the attitude towards negotiation is integration or bargaining, whether the purpose of the negotiation is relationship or contract, and whether the negotiating strategy is planned or improvised. The findings show that $54 \%$ of participants consider a negotiation as a way to build relationship, which means the participants purport to have faith in each other and are not for a single deal. About $46 \%$ of participants think that their primary purpose is to sign a contract as a regular business task (Figure 7).

\section{Negotiation Purpose}

$\begin{array}{lll}54 & & 46 \\ & \text { Relationship Contract }\end{array}$

Figure 7. Negotiation Purpose

When Bangladeshi executives deal with a business, $58 \%$ of them choose an integration attitude, which means finding a joint resolution of the problem to finalize the deal. About $42 \%$ of executives prefer to bargain, which means that they want to trade off concessions between the parties (Figure 8). This result supports the negotiation 
concepts of gains for both parties.

\section{Attitude toward Negotiation}

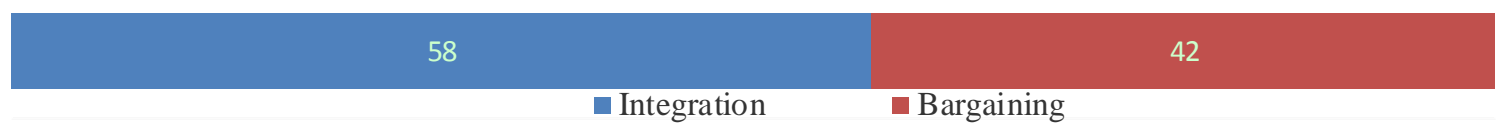

Figure 8. Attitude toward Negotiation

This study finds that about $53 \%$ of negotiators believe in a collaborative process in which both parties extend their hands to gain something, although a competitive process in which both parties struggle to win in business dealings is not far behind (47\%) (Figure 9). The result shows that the tendency is to avoid confrontation (Barros $\&$ Prates, 1996).

\section{Basic Concept of Negotiation}

$53 \quad$ Collaboration $\quad 47$

Figure 9. Basic Concept of Negotiation

Negotiation strategy has a more extreme result in that $80 \%$ of the participants are very professional and target-oriented. With respect to planning and preparation for negotiations, Bangladeshis are very agile and prepared (Figure 10). They attend meetings with superb preparation, documentation, and security, with knowledge about the meeting, time, and venue. This attitude plays a vital role that helps them to enter the meeting with high preparation and succeed therein. As this result implies the importance of planning and preparation for the success of a negotiation (Lewicki et al., 2003; Karrass, 1970), Bangladeshi negotiators are very formal in planning, which is confirmed by the results (Barreto et al., 2004). When planning and preparation is considered to be the norm, then Bangladeshi negotiators are very strong. Improvising implies creativity and the ability to control an unexpected situation, but planning and preparation are considered to be strengths (Carvalhal \& Pereira, 2005).

\section{Negotiation Strategy}

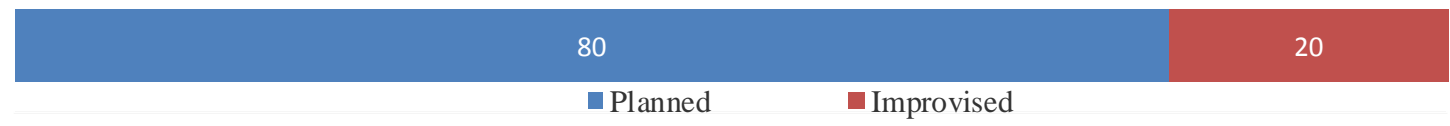

Figure 10. Negotiation Strategy

\subsection{The Role of the Individual}

In any intercultural negotiation, it is important to understand how groups are organized (Salacuse, 1998; 1999). In a culture in which collectivist values are predominant, as in Bangladeshi society, the results with respect to the role of the individual in the negotiation process come as no surprise. Indeed, the business executives responded that negotiators must be subordinated to the interests of the group with which they share responsibilities (75\%) (Figure 11), but in the decision-making process, there is an ambiguity around whether the leaders $(50 \%)$ or the majority $(50 \%)$ of subordinates take responsibility for a negotiation (Figure 12). Leaders as well as subordinates have control in decision-making. In other words, Bangladeshi negotiators believe that the group and the relationships between the group's members are more important than individual aspirations, which can be explained by the collectivist nature of the culture.

\section{Responsibility}

$\begin{array}{ll}25 & 75 \\ & \text { Indivdual } \quad \text { Group }\end{array}$

Figure 11. Responsibility 


\section{Decision Making Process}

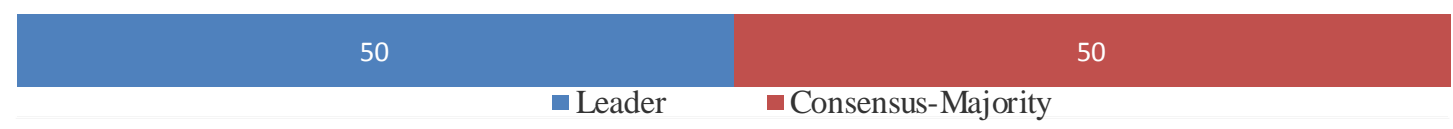

Figure 12. Decision-making Process

Our findings are a reflection of the high risk aversion of Bangladeshi culture. It is found that shared decisions and responsibilities decrease risk because of the multiplicity of perspectives and information. Bangladeshi negotiators very much tend to share risk in decision-making. Negotiators from Asian cultures, such as China, show even more commitment to the group, giving preference to consensus and team negotiations as a way of reaching decisions (Hendon et al., 1996). The results also indicate signific ant differences among regions with respect to the role of the individual in a negotiation. This finding can be explained as the leader holding a limited concentration of power.

\subsection{Uncertainty and Time}

As shown in Figures 13, 14, and 15, the survey outcomes explain the attitudes of Bangladeshi negotiators toward risk taking when negotiating. Seventy-five percent of respondents are conservative in negotiations in that they abide by rules and follow control mechanisms. The remaining twenty-five percent say that a negotiator should bring innovation to negotiations and consider that this mentality may create some risks.

\section{Risk Taking Attitude}

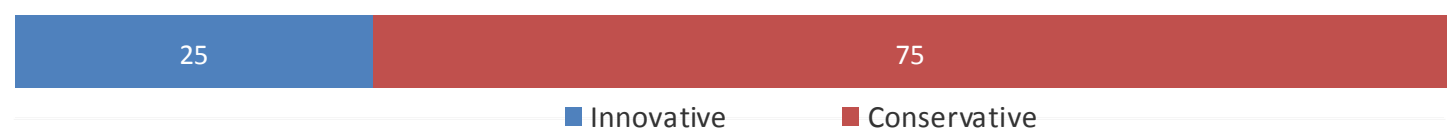

Figure 13. Risk-taking Attitude

Bangladeshi culture reflects the polychronic nature of time (Harris et al., 2004), which is reflected in that 66 percent of respondents report an attitude of flexibility toward time management in the negotiation process (Figure 14). This result indicates that Bangladeshi negotiators are less rigid (34 percent) in sticking to daily activities and a work schedule. They are not concerned with making decisions quickly but rather prefer to wait for their maturation.

Sensitivity To Time-Process

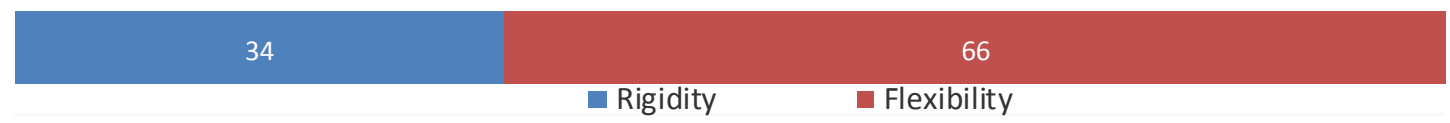

Figure 14. Sensitivity to Time-process

In fact, negotiation can become languid and sluggish, since Bangladeshis like to allow them to reach maturity (58 percent). This attribute affects a culture with more power distance. If the hierarchical distance is greater, interactions among the hierarchy will be fewer, and it will take more time to reach a decision. This result directly relates to the concentration of power. Obtaining approval from different layers of the organization slows the process, and satisfying all parties with the same result is very difficult (Chang, 2003).

\section{Sensitivity to Time-Agreement}

$42 \quad$ Swiftness $\quad$ Maturation

Figure 15. Sensitivity to Time-Agreement

\subsection{Communication}

This section discusses cultural attributes such as polychronic time, risk avoidance, and the home-and-street distance, which are all related to the communication process of negotiation. Bangladeshi executives prefer direct communication (84 percent), depending on an easy and direct process for communicating with their business counterparts. On the other hand, $16 \%$ prefer indirect communication in a negotiation (Figure 16). Bangladeshi executives state that asking for information in a direct manner is the best way to maintain good business terms 
with counterparts. On the other hand, Bangladeshis are more argumentative (54) than they are listeners (46\%), as shown in Figure 17. This cultural characteristic interrupts the business negotiation process when Bangladeshi businessmen talk and discuss with their counterparts in negotiations.

\section{Communication Complexity}

$16 \quad$ Indirect $\quad 84 \quad$ Direct

Figure 16. Communication Complexity

\section{Communication Style}

$\begin{array}{lll}46 & 54 \\ & \text { a Listener } \quad \text { Debator }\end{array}$

\subsection{Role of Emotions}

Figure 17. Communication Style

Bangladeshi business negotiators like to respond quickly to another's claims or challenges (Volkema \& Chang, 1998), referring to the next piece of information. On the other hand, Bangladeshi negotiators place more importance on controlling and repressing emotions. They think that doing so is a vital determining factor of success in a negotiation (72 percent). This finding reveals that a spontaneous response is not always helpful for success (28 percent) (Figure 18). As Bangladesh is a country with a high-context culture, Bangladeshi negotiators are concerned about high power distance and risk avoidance.

\section{Role of Emotions}

$28 \quad 72$

Figure 18. Role of Emotions

\subsection{Trust}

Trust or distrust is a vital component of the interpersonal dynamic for building a relationship in a negotiation (Tuchinsky et al., 1994). The result derived from interpersonal trust shows that 67 percent of participants state that they start a meeting or negotiation with faith in their counterpart and an open mind (Figure 19). On the other hand, about 33 percent of participants enter into a negotiation process with distrust and a blocked mind. Bangladeshi negotiators trust their counterparts, as they are also part of their social circle and have a continuing relationship. Howe ver, this result contradicts the finding on argumentativeness. Written contractual details and the importance of the validity of a contract are also important.

\section{Interpersonal Trust}

$\begin{array}{lll}67 & & \\ & \text { - Trust } \quad \text { Distrust }\end{array}$

Figure 19. Interpersonal Trust

\subsection{Protocol}

As shown in Figure 20, Bangladeshi negotiators prefer a formal presentation during a negotiation. About 58 percent of the participants prefer a formal presentation, which reveals professionalism and formalism. 
Presentation and Appearance

58
Formal Presentation $\quad$ Informal Presentation

Figure 20. Presentation and Appearance

\subsection{Outcomes}

The last outcomes of this survey demonstrate the features of formalism, risk aversion, and power distance. About 73 percent of the participants agree that the negotiation process and its contents should be specific (Figure 21). This cultural characteristic indicates the formalism, power distance, and risk aversion of Bangladeshi executives, as it implies the certainty of a controlled mechanism. They prefer specification to generic objectives. On the other hand, nearly 70 percent of the participants prefer a top-down process for building up to an agreement (Figure 22), and the other $30 \%$ choose a bottom-up process. This result means that negotiation commences with general guidelines with concepts and definitions and moves forward to complex topics and details.

\section{Content of Contract}

$\begin{array}{cc}27 & 73 \\ & \text { Generic }\end{array}$ Specific

Figure 21. Content of Contract

\section{Process for Building Up the Agreement}

$\begin{array}{ll}70 & \\ \text { Top-Down } & \text { Botton-Up }\end{array}$

Figure 22. Process for Building up the Agreement

As a way of demonstrating the value of the friendship, it is useful to prepare small gifts or a money pocket after an agreement is finalized or on the occasion of contract signing. The Figure 23 shows that 38 percent have a neutral opinion about a gift or money pocket as a symbol of friendship, and 35 ( 25 percent agree +10 percent strongly agree) percent are in favor. This finding is in line with the cultural spectrum of Bangladesh, where people like to exchange gifts with their friends and business partners.

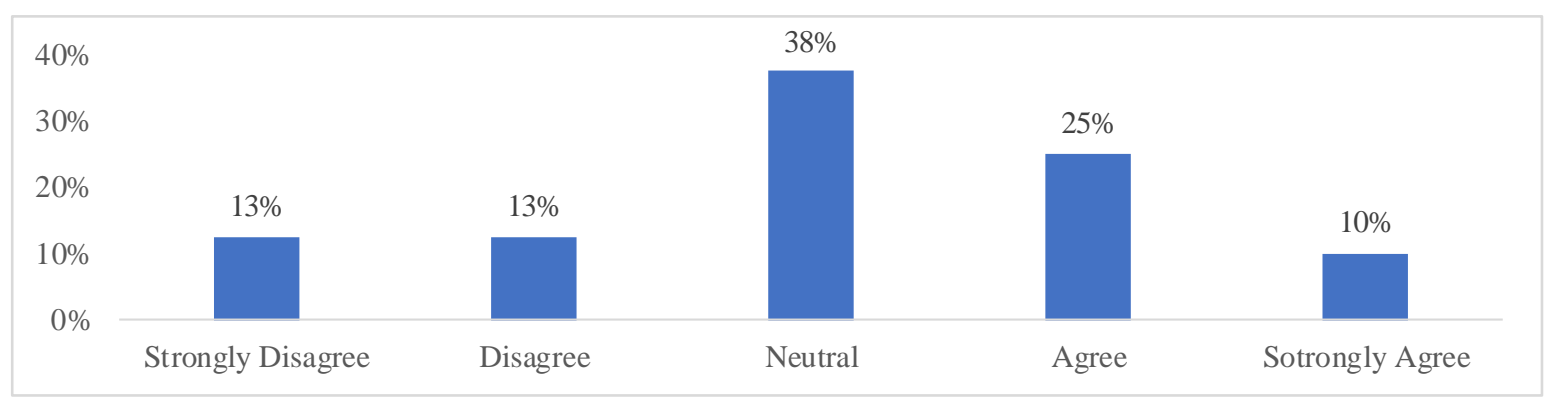

Figure 23. Gift or Money for Friendship

Conscious and subconscious beliefs about corruption are an illusive issue in negotiations in many cultural setting. The Figure 24 reveals that 48 percent of respondents were neutral when asked about corruption, and 35 percent agree that corruption sometimes works. This finding reflects that Bangladeshi strategies toward business negotiation are tactically philosophical. 


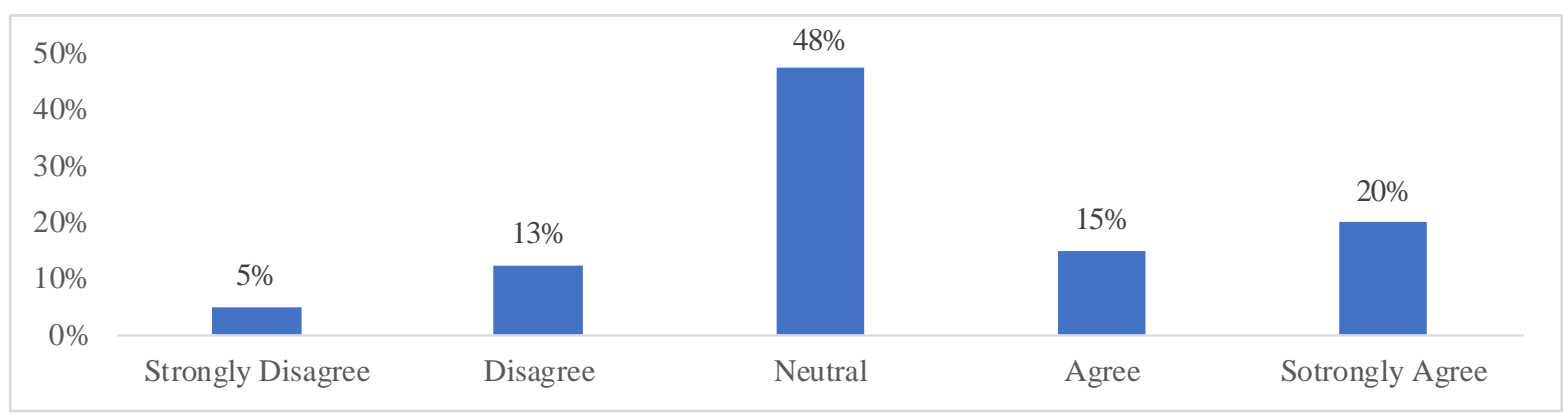

Figure 24. Corruption is an Illusive Issue

\subsection{Problems in Negotiation}

Alist of some common problems arose when negotiators were asked about the nature of problems in negotiation. Respondents were given multiple options. About 33 respondents said that language was a major problem, followed by pricing and timing. Although most of the Bangladeshi executives face different types of problems in negotiation, only $11 \%$ of respondents have received training on negotiation. Our findings are consistent with previous research. Akhter et al. (2009) found that most business organizations in Bangladesh had no arrangements for training program on communication skills and negotiation for their employees. However, the majority of business executives felt that they needed training on communication skills and negotiations for successful business deals with foreign partners. Academic institutions, foreign counterparts, and business organizations in Bangladesh should design and conduct trainings for successful business negotiations.

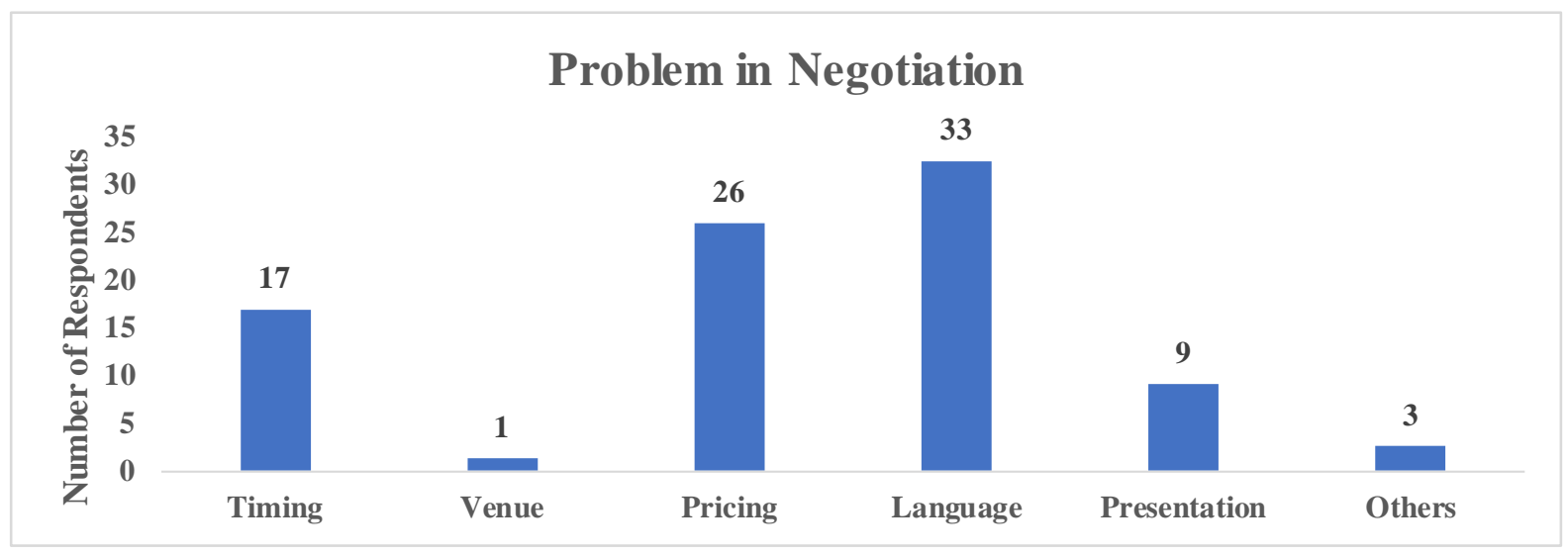

Figure 25. Problem in Negotiation

\section{Management Implications}

From the study and discussion of cultural factors, a picture of the general evidence has emerged on negotiations with Bangladesh counterparts. Several interesting aspects of outcomes and problems in negotiation were found to be related to negotiation characters such as Gift or Money for friendship, Corruption is an illusive issue, negotiation training is sporadic. It is very important to understand the most common basic components of one's counterparty's culture. Bangladeshi business culture is composed of multiple dimensions of values, beliefs, and behaviors that determine everyday business life. Negotiations performed by Bangladeshi business executives are also characterized by these values. When foreign businesspeople desire to do business with Bangladeshis, they should keep in mind that Bangladeshis are concerned with risk aversion, long-term relationships, and direct contacts. Furthermore, negotiation starts from the top level of the organization, as the leader has the most influence in decision-making, followed by subordinates. For a long-term relationship, contracts must be specific and it takes longer to reach a consensus. Building trust and credibility is very vital to the success of a negotiation and a relationship. Assumptions and predictions may kill trust and create barriers in negotiation. Thus, it is suggested not to stereotype.

\section{Conclusion}

Other than the Study on the Cultural Influence on Business Negotiations that has been researched over the past 
decades and is considered an immersive topic for achieving excellence, there are no empirical studies on the influence of culture on business negotiations, particularly from the perspective of an emerging country like Bangladesh. Since multinational corporations have been extending their operations in emerging countries, such a study is critical to examine how culture affects negotiations. Furthermore, among emerging countries, the importance of Bangladesh in the global marketplace continues to grow, so researchers will need to examine and delineate the distinctions of the country.

Considering the above cultural diversity, negotiators are expected to be respectful and observe proper etiquette. To do business with Bangladeshi counterparts, it is important for foreign businessmen to review the Bangladeshi cultural dimensions and their influences in negotiations. Negotiations depend on personal experience, ethical values, and a society's structure. It also depends on the government's policy, the business environment, and other external factors. People with diversified interpersonal interactions with intergroup associations act differently, as culture affects daily activities, family life, society, and business activities at every moment.

All in all, this study initially paves the way for those who are interested in the Bangladeshi culture and provides assistance to those who are negotiating with Bangladeshi partners. This study also provides considerations for further research on negotiations with Bangladeshi counterparts.

\section{References}

Abbasi, B. A., Gul, A., \& Senin, A. A. (2017). Negotiation Styles: A Comparative Study of Pakistani and Chinese Officials Working in Neelum-Jhelum Hydroelectric Project (NJHEP). Journal of Creating Value, 2394964316684239. https://doi.org/10.1177/2394964316684239

Abdullah, A. B. M., Boyle, S., \& Joham, C. (2011). Cultural factors in workforce management: the case of multinational companies operating in Bangladesh. International Review of Business Research Papers, 7(2), 196-211.

Adhikary, B. K. (2010). FDI, trade openness, capital formation, and economic growth in Bangladesh: a linkage analysis. International Journal of Business and Management, 6(1), 16. https://doi.org/10.5539/ijbm.v6n1p16

Ahammad, M. F., Tarba, S. Y., Liu, Y., Glaister, K. W., \& Cooper, C. L. (2016). Exploring the factors influencing the negotiation process in cross-border M\&A. International Business Review,25(2), 445-457. https://doi.org/10.1016/j.ibusrev.2015.06.001

Akhter, N., Khan, S. I., \& Hassan, M. K. (2009). Communication Skill of the Business Executives: An Empirical Study on Some Local Private Business Concerns in Bangladesh. International Business Research, 2(4), 109. https://doi.org/10.5539/ibr.v2n4p109

Barreto, M. A., Gary, M. S., \& Nathan, D. W. (2004). The mobilizing effect of majority-minority districts on Latino turnout. American Political Science Review, 98(1), 65-75. https://doi.org/10.1017/S0003055404001005

Barros, B. T., \& Prates, M. A. S. (1996). Oestilo brasileiro de administrar. Editora Atlas.

BBS (2016). Statistical Pocketbook Bangladesh. Bangladesh Bureau of Statistics, Statistics and Informatics Division, Ministry of Planning, Bangladesh.

Brett, J. M. (2017). Culture and negotiation strategy. Journal of Business \& Industrial Marketing, 32(4). https://doi.org/10.1108/JBIM-11-2015-0230

Carvalhal, A. L., \& Pereira C. R. (2005). Corporate governance index, firm valuation and performance in Brazil. Revista Brasileira de Finanças, 3(1).

Chang, L. C. (2003). An examination of cross-cultural negotiation: Using Hofstede framework. Journal of American Academy of Business, Cambridge, 2(2), 567-567.

Chang, L. C. (2012). Subcultural differences in Taiwanese and Burmese Chinese business negotiation styles. Social Behavior and Personality: an international journal,40(7), 1067-1074. https://doi.org/10.2224/sbp.2012.40.7.1067

David, K. T., Francis, J., \& Walls, J. (1994). Cultural differences in conducting intra-and inter-cultural negotiations: A Sino-Canadian comparison. Journal of international business studies, 25(3), 537-555. https://doi.org/10.1057/palgrave.jibs.8490211

Deresky, H. (2017). International management: Managing across borders and cultures. Pearson Education. 
Elahee, M. N., Kirby, S. L., \& Nasif, E. (2002). National culture, trust, and perceptions about ethical behavior in intra - and cross - cultural negotiations: An analysis of NAFTA countries. Thunderbird International Business Review, 44(6), 799-818. https://doi.org/10.1002/tie.10049

Gelfand, M. J., Brett, J., Gunia, B. C., Imai, L., Huang, T. J., \& Hsu, B. F. (2013). Toward a culture-by-context perspective on negotiation: Negotiating teams in the United States and Taiwan. Journal of Applied Psychology, 98(3), 504. https://doi.org/10.1037/a0031908

Harris, P. R., Moran, R. T., \& Moran, S. V. (2004). Managing cultural differences: Global leadership strategies for the twenty-first century.

Hashim, H. (2010). International negotiation styles: a perspective of Malaysian diplomats, Auckland University of Technology.

Hendon, D. W., Hendon, R. A., \& Herbig, P. A. (1996). Cross-cultural business negotiations. Greenwood Publishing Group.

Hofstede, G. (2017). Cultural Dimensions: Country comparison.

Jiang, Y. (2013). Business Negotiation Culture in China-A Game Theoretic Approach. International Business Research, 6(3), 109. https://doi.org/10.5539/ibr.v6n3p109

Karrass, C. L. (1970). The negotiating game. New York, NY: Thomas Y. Crowell.

Kramer, H. E., \& Herbig, P. (1997). Measuring intracultural bimodality and cross-cultural diversity in American-Japanese business negotiations. Journal of Marketing Communications, 3(3), 187-195. https://doi.org/10.1080/135272697345961

Lewicki, R., Gray, B., \& Elliott, M. (2003). Making sense of intractable environmental conflicts: Concepts and cases. Island press.

Peleckis, K. (2013). International Business Negotiations: Culture, Dimensions, Context. International journal of business, humanities and technology, 3(7), 91-99.

Rahmatullah, M. (2009). Regional Connectivity: Opportunities for Bangladesh to be a Transport Hub. Journal of Bangladesh Institute of Planners, 2, 13-29.

Reaiche, C., de Zubielqui, G. C., \& Boyle, S. (2016). Deciphering innovation across cultures. The Journal of Developing Areas, 50(6), 57-68. https://doi.org/10.1353/jda.2016.0132

Saha, R. C. (2016). Prospectus of Bangladesh in Developing Intermodal Freight Transportation Network in South Asia. Journal of Economics and Sustainable Development.

Salacuse, J. (1991). Making Global Deals: Negotiations in the Global Marketplace. Boston: Hough ton Mifflin .

Salacuse, J. W. (1998). Ten ways that culture affects negotiating style: Some survey results. Negotiation Journal, 14(3), 221-240. https://doi.org/10.1111/j.1571-9979.1998.tb00162.x

Salacuse, J. W. (1999). Intercultural negotiation in international business. Group Decision and Negotiation, 8(3), 217-236. https://doi.org/10.1023/A:1008660330550

Sebenius, J. K. (2002). The hidden challenge of cross-border negotiations. Harvard Business Review, 80(3), 76-85.

Sobral, F., Carvalhal, E., \& Almeida, F. (2008). The Influence of Culture on Negotiati on Styles of Brazilian Executives. Management Research: Journal of the Iberoamerican Academy of Management, 6(2), 107-119. https://doi.org/10.2753/JMR1536-5433060203

Tuchinsky, M., Escalas, J. E., Moore, M. C., \& Sheppard, B. (1994). Beyond Name, Rank and Function: Construals of Relationships in Business. In Academy of Management Proceedings, 1994(1), 79-83. https://doi.org/10.5465/AMBPP.1994.10341728

Van Schendel, W. (2009). A history of Bangladesh. Cambridge University Press. https://doi.org/10.1017/CBO9780511997419

Volkema, R. J., \& Chang, S. (1998). Negotiating in Latin America: What we know (or think we know) and what we would like to know. Latin American Business Review, 1(2), 3-25. https://doi.org/10.1300/J140v01n02_02

Weiss, S. E., \& Stripp, W. G. (1996). Negotiating with Foreign Business Persons: An Introduction for Americans with Propositions on Six Cultures; Working Paper in Preparation for the LAUD Symposium. LAUD. 
World Archaeology (2002). Community Archaeology, 34(2), 346- 362

Yunus, M., \& Yamagata, T. (2012). The garment industry in Bangladesh. Dynamics of the Garment Industry in Low-Income Countries: Experience of Asia and Africa. Chousakenkyu Houkokusho, IDE-JETRO.

\section{Copyrights}

Copyright for this article is retained by the author(s), with first publication rights granted to the journal.

This is an open-access article distributed under the terms and conditions of the Creative Commons Attribution license (http://creativecommons.org/licenses/by/4.0/). 